\title{
Blood-sucking midges' ecology in pastures and cattle farms Of the Tyumen Region
}

\author{
O. A. Fiodorova*, E. I. Sivkova \\ All-Russian Scientific Research Institute of Veterinary Entomology and Arachnology, Branch of Federal State \\ Institution Federal Research Centre Tyumen Scientific Centre of Siberian Branch of the Russian Academy of \\ Sciences, Tyumen, Russia
}

Corresponding author E-mail: fiodorova-olia@mail.ru

Received: 17.07.2020. Accepted: 17.08.2020

\begin{abstract}
The article presents materials on the seasonal dynamics of the population of gnat on pasture and farm, shows the feasibility of protecting cattle from these insects both when grazing, and zero grazing, comparative harmfulness in conditional units, and presumed loss of animal productivity. The purpose of the study is to determine the parasitological situation on insects of the gnat complex, the terms of protection depending on the technology of cattle management. One of the topical tasks for the successful development of livestock in the Tyumen region is to eliminate the harm caused by blood-sucking dipterous insects as hematophages and vectors pathogens of a number of dangerous diseases for humans and animals. When zero grazing indoor there is a mass attack of mosquitoes and black gnats on animals from mid-June to the middle of the first decade of July. The main gnat component in the specified time interval is mosquitoes, which have averaged 2.1 conventional units (c.u.). The malicious population of gnat as a whole during this period amounted to 2.216 c.u., and the estimated loss of productivity of animals $-8.2 \%$. The estimated losses of animal productivity indicate the advisability of protecting animals from gnat, regardless of the technology of their keeping.
\end{abstract}

Keywords: Blood sucking dipterous (gnus); Horse flies; Mosquitoes; Black flies; Seasonal dynamics; Abundance; Animal efficiency loss

\section{Introduction}

Blood-sucking dipterous insects also known as "gnat" include horseflies (Tabanidae), mosquitoes (Culicidae), black flies (Simuliidae), and black gnats (Ceratopogonidae), in Russia they are ubiquitous and cause significant damage to the country's agriculture. The main factors determining the high gnat populations are favorable climatic conditions for their reproduction, abundance of suitable adult (waterbodies and swamps) and imago habitats (wood, shrub or high grassy vegetation), and the presence of warm-blooded host animals. In animal pastures, the number of gnats is usually several times higher than in plain territories. The harmful effects of dipterous insects are determined by the soreness of their pricks, blood loss, intoxication of saliva administered during blood sucking, subsequent inflammatory processes in areas of bites. Parasitization of gnat is also manifested in the form of a general reaction of the organism, accompanied by an increase in body temperature, an increase in the rhythm of pulse and breathing, that is, leads to a deterioration of the overall state, as well as reduction of resistance.

In mass parasitization, the gnat causes severe anxiety of animals, accompanied by numerous protective movements with significant energy loss, disturbance of their normal grazing and rest. In areas of developed livestock, cattle are the main host for the bloodsucking dipterous insects, which decline the cattle productivity. Cattle yield decreases by 15-30 in areas with gnat high concentration in the south of the Tyumen region, and the young cattle reduced their mass by $25-40 \%$. Systematic spraying of cattle by synthetic pyrethroids allows to prevent $11-21 \%$ reduction in dairy productivity and keep thousands of cows in the season at the level 50 to 80 tons of milk (Pavlov, 2001; Kamut \& Jezierski, 2014; Gavrichkin et al., 2018; Fiodorova, 2019; Pavlova \& Sivkova, 2019; Sivkova, 2019; Foster \& Walker, 2019).

The harmful effects of blood-sucking dipterous insects are exacerbated by the fact that they are vectors of many infectious and invasive diseases of humans and animals. Protective measures are necessary to prevent these losses. The number of attackers of blood-sucking dipterous insects determines the expediency, timing and duration of the period of protection of animals; therefore it is necessary to monitor the seasonal dynamics of the number of these insects (Fiodorova, 2019).

In dairy cattle there are two systems of cattle management: all-year stall (zero grazing) or stall-pasture and two methods of housing: tie-up and no-tie (Dolgova, 2012; Rubina, 2017; Nikishina, 2018). Currently, zero grazing is widely applied in cattle management in the south of the Tyumen region during the summer.

We studied the blood-sucking midges' ecology in the southern taiga, where the numerous gnat caused the alleged loss of grazing cows' dairy productivity by $35 \%$ (Pavlov et al., 2007).

\section{Material and methods}

The work was performed in the Laboratory of Entomology and Disinsection of VNIIVEA - a branch of the Tyum NC SORAN and in the southern taiga area of the Tyumen region (Figure 1). The work was carried out in 2017 in pasture and cattle farm in Petrunkino village - LLC PC "Moloko", Nizhnetavdinsky district, Tyumen region (subzone of southern taiga, 57³3' N, 66²11' E). 


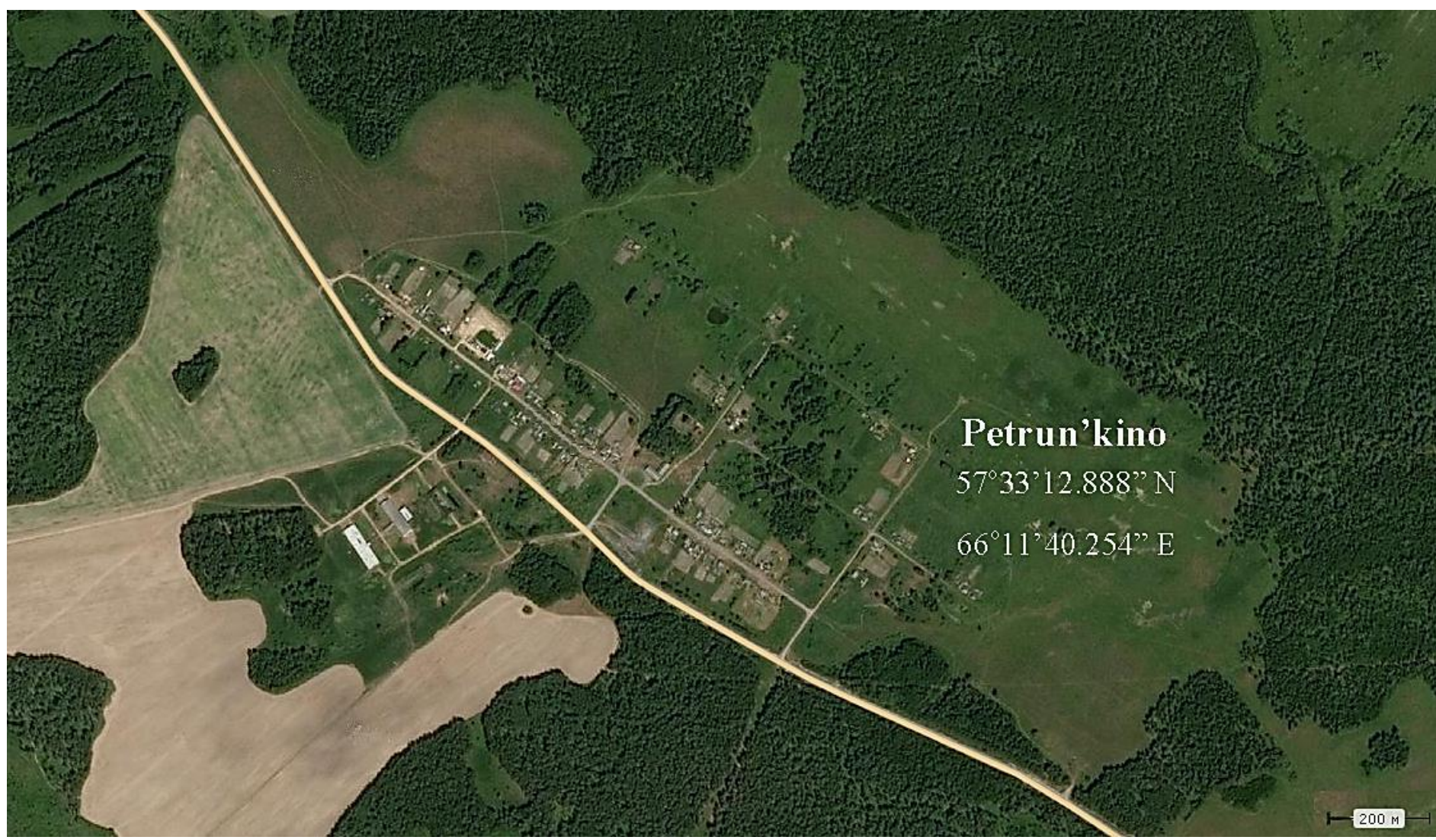

Figure 1. Study area, southern taiga subzone of the Tyumen region (https://kartarf.ru/derevni/petrunkino).

The grazing started on June 15. A herd of young stock from 260 heads at the age of 6-7 months was grazed on the pasture. The animals were kept on a pasture around the clock with night keeping in an open enclosure. Youngsters of an older age - heifers (about 100 heads) were kept in a pen during the day and indoors at night.

Fauna and ecology of blood-sucking dipterous insects were studied by collecting and counting of their population on pasture, farm paddock, and livestock facilities. The horseflies on the pasture was sampled by spinner-type traps during the day and then calculated (Pavlova, 1986; Gavrichkin et al., 2016); the intensity of their attack was evaluated by simultaneous visual surveys in 5-10 repetitions (Konstantinov, 1990). Mosquitos, blackflies and black gnats were monitored for 19-20 hours in two stations on pasture (in open areas and in the forest), in cattle enclosures and premises, and sampled by entomological skimming net with removable bags (Detinova et al., 1978). Average data for 10 swings of 10 repetitions, which corresponded to a one-point attack on animals, were taken for attack intensity assessment. When studying the population seasonal dynamics, the records were carried out for 5 days. We estimated the gnat malicious population quantity in conditional units (c.u.) according to R. P. Pavlova (1997). The economic threshold of 0.8 c.u. registered in single-moment records on animals in the herd, was accepted for the gnat mass flight indicator. Estimated losses of dairy productivity were determined with average malicious number of gnat (c.u.) during their mass flight, where loss of one c.u. was equal to $3.7 \%$. In research stationary, 13 records were carried out on the pasture and on the farm, 17 records were carried out in the paddock on pasture and around the farm. About of 3,500 horseflies, 9,580 mosquitoes, 8,648 blackflies and 2,950 black gnats were collected.

\section{Results and Discussion}

Thus, we collected data on the seasonal dynamics of horseflies, mosquitoes and blackflies number in pasture, their comparative harmfulness, and the estimated loss of animal productivity (Table 1).

\section{Horseflies}

The appearance of the first single horseflies is noted at the end of the first decade of May. However, due to the non-stable weather with cold times until the end of May, they were exceptionally rare. With the warming in early June, their flight became more stable. Monitoring of population during the summer season showed the end of the flight by mid-August. Thus, a steady period of horseflies was observed from the beginning of June to the middle of August that is 2.5 months.

Table 1. Seasonal dynamics of the number of midges in the pasture and estimated loss of animal productivity (specimens and conventional units).

\section{Insects}

\section{Date}

$\begin{array}{llllllllll}12.06 & 18.06 & 23.06 & 29.06 & 3.07 & 8.07 & 15.07 & 19.07 & 23.07 & 28.07\end{array}$




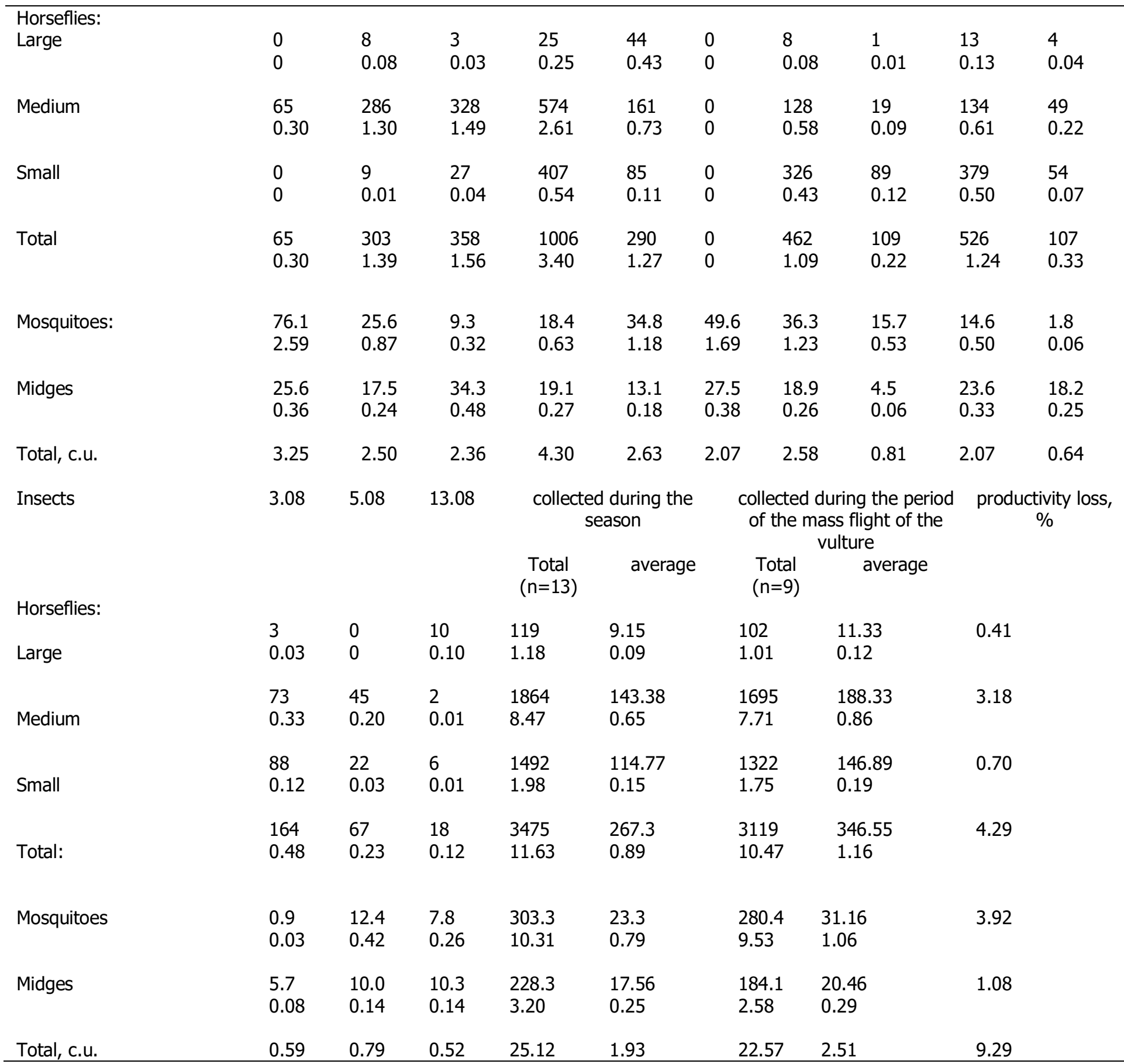

\section{Mosquitoes}

Massive population of horseflies occurred from mid-June to mid of the third decade of July that is about 40 days, interrupted due to weather conditions at the end of the first and significantly decrease at the end of the second decade of July. The peak number is noted at the end of June, when 1006 horseflies, or $3.4 \mathrm{cu}$ were collected by the trap. During this rise in population, the estimated loss of cattle productivity reached $12.6 \%$. The average number of horseflies during the total period amounted to 267 individuals and according to severity corresponded to $0.89 \mathrm{cu}$, which is slightly higher than the economic threshold.

We registered the appearance of mosquitoes after May 20. The mass attacks began around of June 10. Before the cattle were expelled to pasture, there was a peak number of gnat (76.1 insects per count) after June 20 . In the third decade of June, the number of mosquitoes decreased and was below the economic threshold. In the first half of July, the population increased and we observed a mass flight, however they did not reach the initial level. From mid-July to mid-August (the end of observation), mosquito population remained low. Thus, the total period of mosquitos' flight lasted for three months. Wen also observed the mass flight and attacks in June second decade and the first half of July; it was intermittent and lasted for less a month. During the first population wave, the estimated loss of products reached up to $9.6 \%$ and it was $6.3 \%$ during the second peak. The average number of mosquitoes was 23.3 individuals per count or 0.79 c.u. (registered from June 12 to August 13), that was almost the economic threshold.

\section{Blackflies}

We registered low number of blackflies, not exceeding the economic threshold, during the end of May to the middle of August. On average, blackflies amounted to 17.5 individuals per count or $0.25 \mathrm{cu}$ during the season.

We observed gnat mass flight from June 21 to July 25 (approx. 45 days, Fiodorova, 2019). The average malicious population of the gnat was $2.51 \mathrm{c} . \mathrm{u}$, with $1.16 \mathrm{c}$.u. of horseflies, $1.06 \mathrm{c} . \mathrm{u}$. of mosquitoes, and $0.29 \mathrm{c} . \mathrm{u}$. of blackflies. The estimated loss of cattle 
productivity during the gnat mass flight averaged for $9.29 \%$ during the season, reaching up to $15.9 \%$ during the population peak at the end of June (Fedorova et al., 2016, 2017).

When grazing calves managed in an open paddock used for many years during the daytime and at night for the rest, the gnats did not attack them. During 16.06-13.08, the average number of mosquitoes was 0.1 (maximum 0.8), blackflies - 3.45 (maximum 15.6 ), black gnats - 4.45 (maximum 48.2) individuals per count, and single horseflies appeared exceptionally rare. Thus, the expected losses of grazing livestock productivity indicate the economic feasibility of cattle treated with insecticides (Fedorova et al., 2016).

Studies of the gnat population attacking the calves on the farm, with their free movement from indoor to paddock and back, showed that there was little to no attacks in the paddock during daylight hours. We noted only day insects (single horseflies): one insect per 10-15 calves and single blackflies. We also registered the attacks of evening insects - mosquitoes, black gnats, and single blackflies in the room during the rest of cattle in June-July. The most numerous here were mosquitoes from mid-June to mid-first decade of July. The population of black gnats was low with a slight upturn - at the end of the second to the beginning of the third decade of June. The maximum number of mosquitoes in one count reached 89 , while the black gnats reached 79 . The average number of mosquitoes amounted to 61.7 individuals (2.1 c.u.), black gnats - to $28.43(0.14$ c.u.) and black flies - to $0.2(0,002$ c.u. $)$, and the malicious number of the entire gnat varying from 1.63 to $3.02 \mathrm{c}$.u. was $2.216 \mathrm{c}$.u. per count during gnat mass attacks in the farm premises from mid-June to the middle of the first decade of July (20 days). According to this population of gnat, the estimated productivity losses averaged by $8.2 \%$ with a maximum of $11.2 \%$ at the beginning of July, indicating the economic feasibility of protecting animals housed with zero-grazing indoor system.

We revealed that gnat flying was lasted from the third decade of May until mid-August (about three months). The mass flight was from June 20 until July 15 (ca. 45 days). During this period, the malicious number of the gnat population amounted to 2.51 cu., consisted of horseflies (1.16 c.u.), mosquitoes (1.06 c.u.) and blackflies (0.29 c.u.). The estimated loss of cattle productivity during the grazing was $9.29 \%$. We registered a mass attack of mosquitoes and black gnats on cattle housed with zero-grazing indoor system, from mid-June to the middle of July first decade (approx. 20 days). The main component of the gnat were mosquitoes (2.1 c.u.). The malicious population of gnat during this period was $2.216 \mathrm{cu}$, and the estimated loss of cattle productivity was $8.2 \%$. We suggested that the alleged losses of animal productivity indicate the expediency of protecting animals from gnat regardless their breeding. We recommended treating the cattle with insecticides when grazing during the mass gnat presence. In case of zero-grazing housing, in open stalls during the day and in the livestock room at night, the protection of animals must be carried out by disinfection (spraying) of livestock premises using long residual insecticides at the end of May.

\section{Acknowledgements}

The article was financially supported by FNI "Monitoring of the epizootic situation and forecasts of the development of possible outbreaks of parasitic animal diseases".

\section{References}

Detinova, T.S., Rasnitsyn, S.P., Markovich, N.Ya. (1978). Unification of methods for counting the number of blood-sucking Diptera insects. Honey Parasitol, 5, 84-92 (in Russian).

Dolgova E.A. (2012). The main factors for the effective management of dairy cattle breeding. Innovations and Investments, $1,125-128$. Fedorova, O.A. (2019a). A method for calculating cattle productivity losses caused by an attack of a gnat complex. Theory and practice of controlling parasitic diseases, 20, 650-655.

Fiodorova, O.A. (2019b). Circadian activity rhythm of blood-sucking midges (Diptera Simuliidae) in different natural and climatic subzones of the South of Tyumen Region. Ukrainian Journal of Ecology, 9(1), 193-203.

Fedorova, O.A., Gavrichkin, A.A., Khlyzova, T.A., Sivkova, E.I. (2016). Distribution of blood-sucking midges (Diptera Simuliidae) in landscape and geographical zones of the south of the Tyumen region. Bulletin of the agro-industrial complex of Stavropol, 1(21), 83-86 (in Russian).

Foster, W.A., Walker, E.D. (2018). Mosquitoes (Culicidae). Pp. 261-325. In Medical and Veterinary Entomology (Third Edition). Mullen, G., Durden. L. (Eds.). Academic Press.

Gavrichkin, A.A., Khlyzova, T.A., Fedorova, O.A., Sivkova, E.I. (2016). Protection of farm animals from blood-sucking dipterans in the Tyumen region (review). Tauride Bulletin of Agricultural Science, 2(6), 36-47 (in Russian).

Gavrichkin, A.A., Fedorova, O.A., Sivkova, E.I., Siben, A.N. (2018). The etology of blood-sucking midges (Diptera: Ceratopogonidae) while attacking animals. International Journal of Pharmaceutical Research, 10(4), 305-309.

Guidelines for the use of traps for collecting, accounting for the abundance and extermination of horseflies on pastures. (1986). Moscow (in Russian).

Kamut, M., Jezierski, T. (2014). Ecological, behavioural and economic effects of insects on grazing farm animals -- a review. Animal

Science Papers \& Reports, 32, 2, 107-119.

Konstantinov, S.A. (1990). Features of the attack of horseflies and mosquitoes on cattle on the pastures of the north-west of the RSFSR. Thesis of Doctoral Dissertation. Leningrad (in Russian).

Nikishina A.V. (2018). Milk productivity of cows depending on the influence of various factors. Proceed. XV Int. Sc. Conf. Experimental and theoretical studies in modern science. Novosibirsk. SibAK, 6 (15), 50-56.

Pavlov, S.D., Pavlova, R.P. (2001). The state of research and the prospects for protecting animals from gnats and pasture flies. Collections All-Russian RDI Veterinary Entomology and Arachnology, 43, 181-193.

Pavlov, S.D., Pavlova, R.P., Khlyzova, T.A., Fedorova, O.A. (2007). Decrease in milk productivity of cows depending on the number of midges on pastures and the effectiveness of protective measures. Collections All-Russian RDI Veterinary Entomology and Arachnology, 49, 160-174 (in Russian).

Pavlova, R.P. (1997). Comparative harmfulness and economic thresholds of harmfulness of blood-sucking diptera insects for dairy cows. Collections All-Russian RDI Veterinary Entomology and Arachnology, 38, 112-130 (in Russian).

Pavlova, R.P., Sivkova, E.I. (2019). Faunal overview of horseflies (Diptera, Tabanidae) of Tyumen region. Ukrainian Journal of Ecology, 9(2), 57-67.

Rubina, M.V. (2017). The effectiveness of milk production in different systems of keeping cows. Actual problems of the intensive development of animal husbandry, 122-128 (in Russian). 
Sivkova, E.I. (2019). The harmful effects of horseflies (Diptera, Tabanidae) on animals and humans. Theory and practice of controlling parasitic diseases, 20, 575-579. DOI: 10.31016/978-5-9902340-8-6.2019.20.575-579

\section{Citation:}

Fiodorova, O.A., Sivkova, E.I. (2020). Blood-sucking midges ecology in pastures and cattle farms of the Tyumen Region. Ukrainian Journal of Ecology, 10(4), 43-47.

(c) $\mathrm{EY}$ This work is licensed under a Creative Commons Attribution 4.0. License 